American Journal of Applied Sciences 5 (10): 1384-1391, 2008

ISSN 1546-9239

(C) 2008 Science Publications

\title{
Perceptions of Paddy Farmers towards Sustainable Agricultural Technologies: Case of Haraz Catchments Area in Mazandaran province of Iran
}

\author{
${ }^{1}$ A. Bagheri, ${ }^{2}$ H. Shabanali Fami, ${ }^{2}$ A. Rezvanfar, ${ }^{2}$ A. Asadi and ${ }^{3}$ S. Yazdani \\ ,${ }^{1}$ University of Mohaghegh Ardabili, Ardabil, Iran. ${ }^{2}$ Department of Agricultural Extension and \\ Education, ${ }^{3}$ Department of Agricultural Economics, University College of Agriculture and Natural \\ Resources, University of Tehran, Tehran, Iran
}

\begin{abstract}
Sustainable agriculture has defined and described in many ways. Despite the diversity in conceptualizing sustainable agriculture, there is a consensus on three basic dimensions of the concept, namely, ecological soundness economically viable and socially acceptable. The dimensions of ecological soundness refers to the preservation and improvement of the natural environment. Environmental issues emerge from the human use of natural resources. Farmers' decisions to adopt a new agricultural technology depend on complex factors. One of the factors is farmers' perception. The objective of this study was to investigate perceptions of paddy farmers towards applying sustainable agricultural technologies and to identify factors influencing their perceptions. The results of the study show that farmers had good perception about sustainable technologies such as diversification and rotation, application of manure but in general, they preferred modern technologies to local ones. They perceived agrochemicals as the best means to combat against pests and to increase rice production. Their perception of intangible impacts of modern technologies was weak. It was found that there should be a relationship between a numbers of socio-economic factors, such as human capital factors, information sources use, extension participation and landholding size and the perception towards selected sustainable agricultural technologies. Also, educational level, contact with agricultural experts and extension participation were best predictors of their perceptions.
\end{abstract}

Key words: Perception, technology, sustainable agriculture, paddy farmers

\section{INTRODUCTION}

Rice is the world's most important food crop and a primary source of food for more than half of the world's population $^{[18]}$. In Iran, rice is, after wheat, the second major food staff for people.

Major advances have occurred in the food production during the last four decades due to green revolution technology ${ }^{[18,28,30]}$. The technological advances that led to dramatic achievements in the world food production during the last 40 years by adoption of green revolution technology was facilitated by: (1) development of irrigation facilities, (2) availability of inorganic fertilizers; (3) benign government policies ${ }^{[18]}$.

As Roling and Pretty ${ }^{[30]}$ argued, during the past fifty years, agricultural development policies have been remarkably successful at emphasizing external inputs, such as pesticides, inorganic fertilizers, and tractors as the means to increase food production. These external inputs have, however, gradually substituted for natural processes and resources, rendering them less powerful. Pesticides have replaced biological, cultural and mechanical methods for controlling pests, weeds and diseases; inorganic fertilizers have substitute for livestock manures, composts, and nitrogen fixing crops; and fossil fuels have substituted for locally generated energy sources. This argument supported by several empirical studies ${ }^{[5,26,27,28]}$.

Generally, agriculture of this period emphasized on productivity ${ }^{[28]}$ Agricultural development in Iran was not an exception of this path of development. In Iran, for example, fertilizer use increased from 36.000 tons in $1960^{[20]}$ to 800,000 tons in $1980^{[21]}$. Agrochemicals application also increased rapidly ${ }^{[17]}$. While prior to land reform (1962), there were 5,000 tractors in $\operatorname{Iran}^{[20]}$, by the end of the 1980s there were 80,000 tractors operating in the country ${ }^{[3]}$.

After aforementioned period, it was felt that high productivity of conventional agriculture had been achieved at the cost of massive damage to the natural environment and troublesome social disruptions ${ }^{[1]}$. Hence, despite the dramatically quantitative achievements of modern agriculture, in the early of 1980s the green revolution technologies were criticized

Corresponding Author: A. Bagheri, College of Agriculture, University of Mohaghegh Ardabili, Ardabil, Iran 
seriously ${ }^{[1,19,26,28]}$. This concern has promoted a number of initiatives to promote the adoption and diffusion of more sustainable agricultural technologies ${ }^{[13]}$.

As Rahman ${ }^{[26]}$ quoted, delayed consequences of Green Revolution technology on the environment and the question of sustainability of agricultural growth received priority only recently.

The basic challenge for sustainable agriculture is to make better use of internal resources. This can be done by minimizing the external input used, by regenerating internal resources more effectively, or by combination of both ${ }^{[30]}$

Intensive nature of the rice cultivation process can impact the environment. Negative effects include reduced soil fertility, water pollution and the emission of green house gases. The intensive use of a limited number of high-yielding rice varieties over a wideranging area and prolonged period of time has reduced genetic diversity. Inefficient use of agrochemicals and pesticides results in pollution and directly harms farmers' health ${ }^{[2]}$. Keeping this in mind, this paper aims to investigate of paddy farmers' perceptions towards applying sustainable agricultural technologies and how they perceive these technologies and to identify factors influencing their perceptions.

Theoretical framework: Sustainable agriculture has defined and described in many ways. For example, the American Society of Agronomy defined sustainable agriculture as the one that, over the long term: (1) enhances environmental quality and the resource base on which agriculture depends, (2) provides for basic human food and fiber needs, (3) is economically viable, and (4) enhances the quality of life for farmers and society as a whole $\mathrm{e}^{[11]}$.

Absolute definitions of sustainable agriculture at global level and over time are not feasible ${ }^{[9]}$. Despite the diversity in conceptualizing sustainable agriculture, there is a consensus on three basic dimensions of the concept $^{[15,24,29,36,37]}$. One of the dimensions is ecological soundness, which refers to the preservation and improvement of the natural environment.

Environmental issues emerge from the human use of natural resources. According to Roling and Pretty ${ }^{[30]}$, sustainability emerges out of shared human experiences, objectives, knowledge, decisions, technology, and organization. Agriculture becomes sustainable only when people have reason to make it so.

Farmers' decisions to adopt a new agricultural technology in preference to other alternative (old) technologies depend on complex factors. One of the factors is farmers' perception of the characteristics of the new technology vis-à-vis that of the existing (old) technology ${ }^{[23]}$. Smathers ${ }^{[33]}$ concluded in his study that, it was likely that the successful adoption of conservation practices would be influenced by a farmer's attitude and perceptions, than any other factor. Alonge and Martin ${ }^{[1]}$, found that farmer's perceptions regarding the compatibility of sustainable practices with their farming systems emerged as the best predictors of adoption of such practices. Sheikh et $\mathrm{al}^{[32]}$ found that attitude towards the use of technology and contact with extension agents were the main factors influencing the adoption of no-tillage practice. Hence, there is a need to find out what farmers' perceptions are with regards to applying selected sustainable agricultural technologies.

Agricultural technology has defined as any behavior or practice that involves the interaction of individuals within the production system ${ }^{[10]}$. For the purpose of this study, sustainable agricultural technologies are represented by technologies which promote the sustainability of rice cropping systems. This paper intends to contribute to the existing literature by providing an empirical analysis of the possibility of applying sustainable agricultural technologies from the view points of paddy farmers. The results obtained in the analysis are used to develop recommendations for sustainability of rice cropping systems.

\section{MATERIALS AND METHODS}

Descriptive survey design for data collection was adopted in the present study. The population of the study was consisted of 80000 rural households living in Haraz catchments rural area of Mazandaran province in Iran. They were all involved in 84000 ha of rice- based production systems and they were partially or wholly dependent to rice cultivation to earn their livelihoods. The sample included 170 farmers that were determined according to Cochran's formula. Stratified random sampling method was used in the selection of the respondents.

A self- made questionnaire including fixedresponse and open- ended questions was the main instrument for data collection. To validate the instrument, the content validity was used. The instrument was validated by a team of experts consisting of four associate and assistant professors in the Tehran University's Department of Agricultural Extension and Education and two experienced extension rice specialists of the research area. Earlier, a pilot study was conducted in one of the rural area with collaboration of 30 people. The aim of the pilot study was to test and improve the instrument. However, Cronbach's alpha computed to measure the reliability of perceptions towards sustainable agricultural 
technologies indicated that it was 0.85 . It meant that index had high reliability. Having tested the questionnaire for validity and reliability it was filled out by researcher and then the collected data were analyzed. Farmers' perceptions towards sustainable agricultural technologies were operationalized as the extent of their agreement with the statements related to 10 selected indicators of sustainable agriculture which were obtained from review of literature $^{[1,4,5,7,9,13,14,16,22,31,35]}$. With consideration to rice cropping system's situation, the selected indicators of sustainable agriculture included negative effects of agrochemicals on environment and human health, reduced use of agrochemicals in agriculture, use of organic (animal and green) manure, retaining crop remains and wastes on farm after harvesting, low tillage, crop rotation and farm diversification, cultivation of legume after rice harvesting, biologic and agronomic control of pests. The perceptions of farmers towards selected sustainable agriculture indicators measured by some positive and negative statements. Box 1 depicts these indicators and it's statements.

The respondents were asked to indicate the extent of their agreement on each indicator using a Likert-type five-points continuum like strongly agree, agree, undecided, disagree and strongly disagree with assigned scores of $5,4,3,2$ and 1 , for positive statements, respectively and vice versa for negative statements.

\section{RESULTS AND DISCUSSION}

The demographic characteristics of the respondents showed that they were low educated, fairly aged and experienced. About $34 \%$ of the respondents belonged to the age group ranging from 20 to 40 years old, followed by $37 \%$ and $29 \%$ to the age ranges in $4-50$ and $51-81$ years of age, respectively. The mean age of the respondents was 46.6 years.

The results also showed that farming experience of $86.5 \%$ of the respondents was more than 10 years. Their mean years of farming experience were 27.7 years. In the case of education level, $10.6 \%$ of the respondents were illiterate. The education level of 23.5, 25.3 and $27.7 \%$ of them was primary, high school, and diploma, respectively and $12.9 \%$ of the respondents had completed a college level education. Generally, only $5.9 \%$ of the respondents were graduated from agricultural schools or colleges.

Regarding occupation, all of the respondents reported agriculture (rice cropping, gardening and livestock sector) as their major occupation. Whereas, due to small land holdings, $43.5 \%$ of them had nonBox 1: Selected indicators of sustainable agriculture and their statements farm incomes. In the case of land holdings, there were two land possession systems: Land ownership and sharecropping systems. Regarding landownership, 7.7\% of the respondents were landless, $48.2 \%$ of them owned less than one ha of rice farm, followed by $39.4 \%$ and $4.7 \%$ owned $1.1-3$ and $3.1-6$ ha of rice farm respectively, with a mean farm size of 1.4 ha. In the other words, the majority of them were small- scale farmers. Meanwhile, $73.5 \%$ of the respondents were working on their own farms, out of whom $26.5 \%$ regardless of having or not having owned farm, worked as sharecroppers in the landlords' farms.

The respondents were asked to give their response on a Likert scale (never $=0$, rarely $=1$, sometimes $=2$, often $=3$ and always $=4$ ) regarding their use or advisory contacts with the sources/channels of information. On the basis of CV (Coefficient of Variation) and mean, their contacts have prioritized. The mean scores and CVs showed that consultations with other farmers and advisory contacts with district extension agents placed on the highest priorities of the respondents, respectively. TV's agricultural programs, consultation with family members and contact with local extension agents (co- extensions) were placed on the subsequent priorities. Other farmers who placed on the highest priority of the respondents' preference are not knowledgeable sources of information of sustainable agriculture. On the contrary, the most important source of information for sustainable agriculture i.e. agricultural publications had the least priority. It indicates that they had inadequate access to reliable information sources, such as extension, which may be due to their low level of literacy and inattentiveness to writing materials. It will be an alarming for agriculture to become sustainable.

The respondents' participation in four extension activities surveyed on a Likert scale. According to the means and coefficients of variation (CV), their extension participation was prioritized. Participation in extension training courses enjoyed the highest priority. Participation in other activities was unnoticeable.

According to the participation scores, the respondents were grouped into four categories. The respondents who did not participate in extension were placed in the first group (low participation). The participation of $51.8,8.2$ and $3.5 \%$ of the other respondents were low, medium and high, respectively. It indicates that the paddy farmers in the study area had very low access to extension. Meanwhile, the field observations showed that the limited extension activities biased toward the small groups of farmers known as rural extension agents. But they were not 
Indicators

Negative effects of agrochemicals

Reducing use of fertilizers

Reducing use of pesticides

Application of animal manure

Increasing application of green manure

Retaining plant residues

Minimum tillage

Crop diversification and rotation

Cultivation of legume crops

Integrated biological and cultural pests' control
Statements :( Do you think :)?

Agrochemicals are pollutants of environment?

Over use of agrochemicals is detrimental for human and animal health?

By decreasing chemical fertilizer use in long term paddy farmer's benefit will be increased (N)?

Rice yield can be increased only by increased use of chemical fertilizer $(\mathrm{N})$ ?

Pesticides use is the most appropriate method for pest control $(\mathrm{N})$ ?

Herbicide use is the most appropriate method for weed control $(\mathrm{N})$ ?

Pesticide overuse may be lead to pest resistant to pesticides?

Application of animal manure can increase soil fertility?

Application of animal manure can not increase rice production $(\mathrm{N})$ ?

A part of fertilizer needed for rice can be replaced by manure?

Because of presence of chemical fertilizer there is no need to green manure $(\mathrm{N})$ ?

Soil fertility of paddy farm can be improved by application of green manure?

Retaining the plant residues may increase weeds $(\mathrm{N})$ ?

Release of crop residues in paddy farm will decrease soil fertility (N)?

Rice pests' population can be controlled by retaining of crop residues in farm?

Minimum tillage reduces soil erosion, disturbance and exposure?

Successive cultivation of a single crop causes pests' invasion to be increased?

Crop diversification and rotation cause pests' invasion to be decreased?

Crop diversification and rotation is cause of soil erosion $(\mathrm{N})$ ?

Crop diversification and rotation decreases farmer's income (N)?

Cultivation of legume crop improves soil fertility?

Cultivation of legume crop causes pest's invasion to be increased (N)?

Biologic control and weeding of rice farm are the best methods of pest control?

Winter plough of rice farm reduces damage of weeds and stem borer worm?

Table 1: Percent distribution of the respondents according to agreement with the statements of sustainable indicators ( $\mathrm{n}=170$ )

\begin{tabular}{|c|c|c|c|c|c|c|c|c|c|}
\hline Indicators & $\begin{array}{l}\text { Statements } \\
\text { (No.) }\end{array}$ & $\begin{array}{l}\text { Strongly } \\
\text { agree }\end{array}$ & Agree & Undecided & Disagree & $\begin{array}{l}\text { Strongly } \\
\text { disagree }\end{array}$ & Mean & $\mathrm{CV}$ & rank \\
\hline \multirow[t]{2}{*}{ Negative effects of agrochemicals } & 1 & 17.6 & 24.7 & 15.9 & 30.6 & 11.2 & 3.07 & .43 & 15 \\
\hline & 2 & 52.9 & 40.6 & 1.8 & 2.9 & 1.8 & 4.14 & .25 & 2 \\
\hline \multirow[t]{2}{*}{ Reducing use of fertilizers } & 1 & 4.7 & 12.4 & 22.9 & 40.0 & 20.0 & 2.48 & .45 & 17 \\
\hline & 2 & 17.6 & 39.4 & 12.4 & 25.3 & 5.3 & 2.61 & .46 & 18 \\
\hline \multirow[t]{3}{*}{ Reducing use of pesticides } & 1 & 28.2 & 53.5 & 5.3 & 10.0 & 3.0 & 2.06 & .49 & 21 \\
\hline & 2 & 48.8 & 42.3 & 2.4 & 4.7 & 1.8 & 1.68 & .52 & 23 \\
\hline & 3 & 8.2 & 36.5 & 18.8 & 25.9 & 10.6 & 3.06 & .38 & 11 \\
\hline \multirow[t]{3}{*}{ Application of animal manure } & 1 & 35.9 & 52.9 & 2.3 & 7.1 & 1.8 & 4.14 & .22 & 1 \\
\hline & 2 & 2.4 & 17.6 & 3.5 & 67.1 & 9.4 & 3.64 & .26 & 4 \\
\hline & 3 & 4.7 & 34.1 & 6.5 & 46.5 & 8.2 & 2.81 & .40 & 12 \\
\hline \multirow[t]{2}{*}{ Increasing application of green manure } & 1 & 32.3 & 34.1 & 15.9 & 15.9 & 1.8 & 2.21 & .50 & 22 \\
\hline & 2 & 2.3 & 67.1 & 12.4 & 14.1 & 4.1 & 3.49 & .26 & 5 \\
\hline \multirow[t]{3}{*}{ Retaining plant residues } & 1 & 18.8 & 40.0 & 18.8 & 18.8 & 3.6 & 2.48 & .45 & 17 \\
\hline & 2 & 22.9 & 31.2 & 28.2 & 15.9 & 1.8 & 2.42 & .44 & 16 \\
\hline & 3 & .60 & 2.9 & 14.1 & 40.0 & 42.4 & 1.79 & .47 & 20 \\
\hline Minimum tillage & 1 & 5.3 & 7.6 & 21.2 & 44.1 & 21.8 & 2.31 & .46 & 19 \\
\hline \multirow[t]{4}{*}{ Crop diversification and rotation } & 1 & 11.8 & 44.1 & 21.2 & 19.4 & 3.5 & 3.41 & .30 & 7 \\
\hline & 2 & 5.3 & 25.3 & 35.9 & 24.7 & 8.8 & 2.94 & .35 & 8 \\
\hline & 3 & 12.4 & 19.4 & 44.1 & 21.8 & 2.3 & 2.82 & .35 & 9 \\
\hline & 4 & 8.2 & 34.1 & 10.6 & 29.4 & 17.7 & 3.14 & .41 & 13 \\
\hline \multirow[t]{2}{*}{ Cultivation of legume crops } & 1 & 4.1 & 63.0 & 18.2 & 11.2 & 3.5 & 3.53 & .25 & 3 \\
\hline & 2 & 12.4 & 27.7 & 44.1 & 12.9 & 2.9 & 2.66 & .36 & 10 \\
\hline \multirow[t]{2}{*}{ Integrated biological and cultural pests' control } & 1 & 1.2 & 24.7 & 22.9 & 32.4 & 18.8 & 2.57 & .42 & 14 \\
\hline & 2 & 5.9 & 52.9 & 17.1 & 20.6 & 3.5 & 3.37 & .26 & 6 \\
\hline
\end{tabular}

operative in propagating the extension messages particularly, with regard to promoting adoption of sustainable technologies of paddy cultivation.

Perceptions of Sustainable Agricultural Technologies: Table 1 depicts the respondents' perceptions towards sustainable agricultural indicators. In Table 1, numbers of statements related to each indicator inserted.
The respondents' perceptions prioritized according to means and CVs. Because CV depicts the variation of perceptions, lower $\mathrm{CV}$, i.e. lower variation of the respondents' perceptions, for same mean, placed on higher rank. Because of belonging more than one statement to each indicator, it was not possible to organize statements according to their rank order.

As data show, the respondents were fairly aware of the adverse environmental impacts of applying agrochemicals and their ingredients on human and 
animal health. As Rahman ${ }^{[26]}$ also found, while, their awareness remains mostly confined within visible impacts, their perception of intangible impacts was weak.

As mean scores depicts, majority of the respondents were in agreement with the application of agrochemicals. They perceived agrochemicals as the best means to increase production at the present time. Most of them were against the idea of reducing the application of fertilizers and did not believe the process would lead to long term viable production. They insisted on insecticide application as the easiest way to combat against pests, despite the awareness that insecticides are the major environment pollutants and their overapplication makes insects resistant. This result was confirmed by Roling and Pretty ${ }^{[30]}$.

Perceptions of the respondents about organic manure can be analyzed associated with fertilizer. Mean scores of the influence of these manures on improving soil fertility indicates that the respondents had positive perceptions about it. In fact, the easy access to chemical fertilizer made negative perception about the application of these manures. Because, mean scores of replacing fertilizer by manure indicates that the respondents didn't consider a great weight for the manure. In fact, they perceived chemical fertilizer as a valuable elixir. Thus, in spite of positive perceptions about manure, as Roling and Pretty ${ }^{[30]}$ argued, agrochemicals as external inputs is substituting for natural processes and resources, rendered them less powerful.

Despite the numerous emphases on retaining plant residues in the preservation of soil texture and nutrients, the respondents did not have very positive perceptions about it. Since stem- borer as the most serious pest of rice spends winter within plant residues as well as because of incomplete decomposition of organic matter in marsh land, most of the respondent of lowlands were opponents to retaining of residue. They regarded setting fire on the plant residue as the easiest way to get rid of stem borer. Therefore, they should be taught the proper management of residues by the extension agents.

Mean scores of minimum tillage showed that the respondents had poor perceptions about it. Most of them thought the more tillage, the better bed for rice and the more rice yield. Whereas, results of an experiment carried out during 2003-2005 cropping season in the Rice Research Institute of Iran, Rasht ${ }^{[25]}$, showed that minimum tillage was the best paddy residual management in regard to reduced costs and time, betterment of soil structure and drainage. However, no tillage could be beneficial with higher seed density and proper fertilizer and weed management for medium texture soils. It should be added that in the study area often rice field tillage practice is done in the flooded plots with running irrigation water among plots after tillage. However improper soil tillage may result in soil structure demolition, splitting soil particles and reducing its hydraulic conductivity and led to erosion enhancement ${ }^{[8]}$.

There were different perceptions towards necessity of diversification and rotation in the rice- based farming systems. As mean scores and CVs show, most of the respondents were well aware that successive cultivation of a single crop causes an increase in pests' invasion. Also, a number of the respondents who applied diversification and rotation in their farming activities strongly emphasized that these practices had increased their farm's yield. Some of the respondents did not diversify their farms. Most of the respondents couldn't apply the method on their farms because of having small land size and flooded fields. Although 30.6 and 31.8 of the respondent were in agreement with decreasing of pest invasion and soil erosion by diversification and rotation, respectively; however, their perceptions was not very positive about such practices. Because soil erosion is an intangible problem, as Rahman $^{[26]}$ showed, perception about intangible impacts are weak. In the case of pest control by diversification and rotation, as mentioned above, a group of respondents who had been benefited rotation in their farms were in agreement with the statement. Their second crop included vegetable, alfalfa, sorghum, rice, barley and rapeseed. The rapeseed growers were a large subgroup who encountered to rapeseed's pest invasion. They thought diversification and rotation were cause of increased pest invasion. They argued every crop has its pest then several crops will bring into farm several pests. It can be resulted that, failure to adopt an innovation (rapeseed) will affect the adoption of other innovations (rotation).

Majority of the respondents perceived that legume crops can improve soil fertility. But most of them $(59.9 \%)$ didn't believe that with rice- legume rotation, pest's population may be controlled.

Most of the respondents had negative perception about biological control of rice pests. This perception is associated with unsuccessful experience of plant protection office for substitution of stem borer insecticide by trichogramma fly. Most of farmers had no access to trichogramma fly. A small number of the respondents (25.9\%) perceived that biological control is best way for control of pests' population under economic threshold. On the contrary, as means and CVs 
Am. J. Applied Sci., 5 (10): 1384-1391, 2008

Table2: Correlation between selected variables and perception towards selected sustainable technologies

\begin{tabular}{ll}
\hline Selected variables & r value \\
\hline Age & $384^{* *}$ \\
Educational level & $0.715^{* *}$ \\
Discipline & $0.584^{* *}$ \\
Years of experience & $-0.385^{* *}$ \\
Extent of cultivated area & $-0.162^{*}$ \\
Extent of share cropping & $-0.311^{*}$ \\
Diversity of rice variety & $-0.159^{*} *$ \\
Out of farm income & $174^{*}$ \\
Contact with county agric experts & $0.331^{*} *$ \\
Contact with district agric. Ext. center & $0.255^{*} *$ \\
Contact with agric. researchers & $0.285^{* *}$ \\
Agricultural publications study & $0.474 * *$ \\
Contact with other farmers & $-0.140^{* *}$ \\
Extension participation & $0.542^{* *}$ \\
\hline$* \mathrm{p}=0.05$ &
\end{tabular}

$* \mathrm{p}=0.05 \quad * * \mathrm{p}=0.01$

show, the majority of the respondents (58.8) perceived winter plough of rice farm as the best way for reducing damage of weeds and stem borer worm.

According to Table 1, scores of all respondents calculated. Then following analyses was carried out.

Correlation Analysis: The results of correlation analysis in Table 2 depicts that there was significant relationship between perception towards sustainable agricultural technologies and variables consisting of age, educational level, educational discipline, years of experience in agriculture, farmer's cultivated area, sharecropping, diversity of farmer's rice varieties, out of farm income, contact with information sources/channels and extension participation.

As Table2 depicts, there was significant negative relationship between age and experience and perception toward sustainable agricultural technologies $(\mathrm{p}<0.01)$. Education level and discipline had significant positive relationship with perception $(\mathrm{p}<0.01)$.This indicates that more educated farmers were younger and had more positive perception towards sustainable agriculture. There was significant negative relationship between farm size and perception $(\mathrm{p}<0.05)$. Also, there was significant negative relationship between sharecropping and perception. These results are confirmed by Carolan ${ }^{[6]}$. There was significant negative relationship between diversity of rice variety and sharecropping and participants' perception $(\mathrm{p}<0.01)$. Farmers who grew more than one rice varieties, at least one of those was improved variety which needed more external input, especially agrochemicals for more production, that is inconsistent with sustainability. Advisory contacts with district and county agricultural experts, researchers and study of agricultural publications as sources of correct use of inputs had significant positive relationship with their perception $(\mathrm{p}<.01)$, but contact with other farmers
Table 3. Results of regression analysis related to perception towards sustainable technologies

\begin{tabular}{llllll}
\hline Var. & Predictor Variables & $\mathrm{B}$ & $\mathrm{Beta}$ & $\mathrm{t}$ & $\mathrm{p}$ \\
\hline- & Constant & 47.975 & - & 32.962 & 0.01 \\
$\mathrm{X} 1$ & Educational level & 3.543 & 0.563 & 11.280 & 0.01 \\
$\mathrm{X} 2$ & Extension participation & 2.462 & 0.359 & 70128 & 0.01 \\
$\mathrm{X} 3$ & Contact with county agric. experts & 1.458 & 0.133 & 2.678 & 0.01 \\
\hline $\mathrm{F}=92.15$ & Sig. $=0.01 \mathrm{R}=.790$ & $\mathrm{R}^{2} \mathrm{adj}=.618$ & & &
\end{tabular}

because of their insufficient scientific information negatively correlated with perception $(\mathrm{p}<0.01)$. Finally, extension participation and the respondent's perceptions were positively correlated.

The result of F-Test showed that the difference between perceptions of the respondents among four township with different rice cropping systems (upland and lowland) was not significant $(\mathrm{F}=0.436 ; \mathrm{p}=0.727)$.

Regression analysis: In order to determine the factors that best predicted a farmer's perception towards the selected sustainable technologies, a multiple regression analysis with stepwise method was carried out. The regression model incorporated all of the independent variables which had significantly correlations with the perception. The dependent variable was the respondent's perceptions towards selected sustainable technologies index, which was defined as their scores obtained from the statements associated with ten selected indicators.

As shown in Table 3, the positive and significant partial regression coefficients of educational level, extension participation and advisory contacts with experts of county agriculture management were found to have a positive effect on the respondents' perception scores toward selected sustainable agricultural technologies. The $\mathrm{R}^{2}$ value of .618 with $\mathrm{F}$ value of 92.15 indicates the power of model for prediction its significance at .01 level of probability and reveals that 61.2 percent of variance in perceptions could be explained by these three variables.

According to Table 3, the following equation can be used to estimate of farmer's perception towards selected sustainable agricultural technologies: $\mathrm{Y}=47.975+3.543(\mathrm{X} 1)+2.462(\mathrm{X} 2)+1.458(\mathrm{X} 3)+\mathrm{e}$

According to the regression equation, educational level had a strong power in predicting of farmers' perception followed by extension participation and contact with experts which are all related to the knowledge of the respondents.

\section{CONCLUSION}

The findings of correlation analysis showed that there was a significant relationship between perception 
toward sustainable technologies and a number of studied variables. Based on the mentioned results, it can be recommended that:

The respondents had negative perception toward some sustainable technologies, such as minimum tillage, reduced use of agrochemicals, mixed use of organic and chemical fertilizer, biologic and cultural control of pests. Extension agents need to teach them the correct methods of using these technologies. To improve such perceptions it is recommended that extension should use special channel such as result demonstration fields, TV program, field day and conducting visit to rice research station and low external input used farms.

Because of the positive effect of extension participation on perception toward sustainable agriculture, extension needs to expand its coverage to access more farmers especially low educated and more aged and experienced farmers who are of the majority of farmers or farm managers in the area of study to change and improve their perception towards sustainable agriculture. Because of many years of extension efforts for diffusing green revolution technologies, it is difficult but not impossible.

By taking into account the low ratio of extension agents to farmers, extension must select and train farmers who are interested in sustainable agriculture and have a tendency to cooperate with extension agencies as contact farmers.

Farm infrastructure of a lot of farmers is not prepared for diversification and rotation. They need consolidation, integration and drainage. Extension agents must organize and train farmers for reformation and improvement of their farms.

Efforts to acquire more rice from a small piece of farm for livelihood resulted in the excess use of external inputs, such as agrochemicals, tractors and so on by many of small scale farmers in the area of study. Alteration of mono-cultured rice farm to diversify farms, especially with animal rearing can improve farmers' livelihood and reduce input overuse.

Farmers had weak perception towards intangible impacts of modern technologies on soil, water and environment. They must think about such important issues.

\section{REFERENCES}

1. Alonge, A.J. and R.A. Martin, 1995. Assessment of the adoption of sustainable agriculture practices: Implications for agricultural education. Journal of Agricultural Education. 3(3): 34-42.
2. Badawi, A.T., 2004. Rice- based production systems for food security and poverty alleviation in the Near East and North Africa. FAO rice conference, Rome Italy.

3. Baibordi, M., 1989. Some of the facilities and obstacles of agricultural development in Iran. In: Proceedings of the First National Congress on Agricultural Development Problems of Iran. Tehran, Iran (in Farsi), pp: 383-415.

4. Basiri, Sh. 1999. Effects of pesticides on food health and bad effects on living organisms. Zeiton (in Farsi) 10: 24-29.

5. Bylin, C., R. Misra, M. Murch and W. Rigterink, 2004. Sustainable agriculture: development of an on-farm assessment tool. A project submitted in partial fulfillment of the requirements for the degree of Master of Science/Master of Forestry/Master of Landscape Architecture at the University of Michigan: $\leq$ http://css.snre.umich.edu>

6. Carolan, M.S., 2005. Barriers to the adoption of sustainable agriculture on rented land: An examination of contesting social fields. Rural Sociology, 70: 387-413.

7. Cho, Y.S. and Z.R. Choe, 1999. Effect of Chinese milk vetch (Astragalus sinicus L.) cultivation during winter on rice yield and soil properties. Korean Journal. Crop Science. 44: 49-54.

8. Choudhary, M.A., A.R. Lal and W.A. Dick., 1997. Long term tillage effects on run off and soil erosion under simulated rain fall for a central Ohio soil. Soil Tillage Resource, 42: 175-184.

9. Cromwell, E., P. Kambewa, R. Mwanza and R. Chirwa, 2001. Impact assessment using participatory approaches: 'STARTER PACK' and sustainable agriculture in Malawi. Agricultural \& Extension Network (AgREN) pp: 112.

10. CTTA, 1992. A method for transferring Technologies to farmers. Washington, D.C.: Academy for Educational Development.

11. Dennis, S., E. Ekanem, S.P. Singh, and Tegenue, 1996. Perceptions and attitudes of small farmers in Tennessee towards sustainable agriculture and some survival strategies. Proceedings of the National Small Farm Conference. Washington, DC 20250.

12. FAO, 2004. International rice commission newsletter. Vol. 53: Proceedings of FAO rice conference.

13. Filho, D.S.H.M., T. young and M. p. Burton, 1999. Factors influencing the adoption of sustainable agricultural technologies: evidence from the state of Espirito Santo, Brazil. Technological Forecasting and Social Change, 60: 97-112. 
14. Ghosh, N., 2004. Reducing dependence on chemical fertilizers and its financial implications for farmers in India. Ecological Economics, 49: 149-162.

15. Hansen, J.W., 1996. Is agricultural sustainability a useful concept? Agricultural Systems, 51: 185-201.

16. Hayati, D. and E. Karami, 1996. Developing an index for assessment of farming systems for applying in socio-economic researches. In: Proceedings of Agricultural Economic conference Iran. (in Farsi) pp: 634-649.

17. Karami, E., 1993. Sustainable agriculture and agricultural policy. In: Proceedings of the Second Symposium on Agricultural Policy of IranShiraz, Iran. (in Farsi) pp: 37-59.

18. Khosh, G., 2004. Harnessing science and technology for sustainable rice-based production systems. FAO rice conference, Rome Italy.

19. Lacy, W.B. and L. Busch, 1994. The role of agricultural research for U.S. food security. In: W. B. Lacy and L. Busch (Eds), Food security in the United States, Boulder, CO: Westview Press, pp: 298- 320.

20. Lahsaeizadeh, A., 1993. Contemporary Rural Iran. Ashgate Publishing Ltd., Aldershot. pp: 348.

21. Malakouti, M.J., 2000. Sustainable agriculture and yield increase through balanced fertilization. Agricultural Education Press, Tehran. (in Farsi). pp: 460.

22. Malik, R.K., S. Mahlak and B.K. Singh, 2000. Conservation tillage technologies and farmer participatory research and extension approaches in Haryana. Proceedings of an international workshop on developing an action programme for farm level impact in rice- wheat systems of the Indo-Gangetic Plains. New Delhi, India.

23. Negatu, W. and A. Parikh, 1999. The impact of perception and other factors on the adoption of agricultural technology in the Moret and Jiru Woreda of Ethiopia. Agricultural Economics, 21: 205-216

24. Pretty, J., 1996. Regenerating Agriculture, Policies and Practices for Sustainability and Self-Reliance. National Academy Press, Washington, DC.

25. Rabiee, M., F. Alinia, A. Moumeni, J. Ali and M. Esfahany, 2006. The effect of paddy residue management practices on rapeseed (Brassica napus L.) grain yield in paddy soils. Proceedings of Agro Environmemt: 521-524.

26. Rahman, S., 2003. Environmental impacts of modern agricultural technology diffusion in Bangladesh: an analysis of farmers' perceptions and their determinants. Journal of Environmental Management 68:183-191.
27. Rahman, S., 2002. Technological change and food production sustainability. In: Bangladesh agriculture. Asian Profile 30: 233-246.

28. Rezaei-Moghaddam, K., E. Karami, J. Gibson, 2005. Conceptualizing sustainable agriculture: Iran as an illustrative case. Journal of Sustainable Agriculture, 27(3): 25-56.

29. Rigby, D., D. Caceres, 2001. Organic farming and the sustainability of agricultural system. Agricultural Systems 68: 21-40.

30. Roling, N. and J.N. Pretty, 1997. Extension's role in sustainable agricultural development. In: Improving agricultural extension, a reference manual. B.E. Swanson; R., P. Bentz and A.J. Sufranko (Eds.), FAO, Rome, Italy.

31. Roosta, K., 1999. Attitudes of model farmers and other wheat grower farmers toward sustainable agriculture. Msc. thesis, University of Tarbiat Modares- Iran (in Farsi).

32. Sheikh, A.D., T. Rehman and C.M. Yates, 2003. Logit models for identifying the factors that influence the uptake of new 'no-tillage' technologies by farmers in the rice- wheat and the cotton-wheat farming systems of Pakistan's Punjab. Agricultural Systems 75: 79 - 95.

33. Smathers, W.M.Jr. 1982. Farmers attitudes: In L.A. Christensen and L. Miranowski (Eds). Perceptions, attitudes and risks: Overlooked variables in formulating public policy on soil and water conservation and water quality. Staff Report (AGES 820129). U.S. Department of Agriculture, Georgia.

34. Solaimani, A. and B. Amiri-Larijani, 2004. Principles of rice better cultivation. Arvij Publication, 1: 303. (In Persia).

35. Theodor R.K., D.D. Rajasekar., G. Selvaraj, and Jawahar D., 2001. Sustainability of diversified farms in Timbiraparani River Commanl area, South India. network, Agricultural research and Extension network paper (AgRen), No.108.

36. Wiren-Lehr, S.V., 2001. Sustainability in agriculture- an evaluation of principal goaloriented concept to close the gap between theory and practice. Agriculture, Ecosystem and Environment 84: 115-129.

37. Zhen L., J.K. Routray, M.A. Zoebisch, G. Chen, G. Xie and S. Cheng, 2005. Three dimensions of sustainability of farming practices in the North China Plain. A case study from Ningjin County of Shandong Province, PR. China. Agriculture, Ecosystems and Environment, 105: 507-522. 